\title{
Research on Improvement of Welding Process of Rail Vehicle with a Metal Tank
}

\author{
Jun Huang \\ The Locomotive and Car Research Institute \\ China Academy of Railway Sciences \\ Beijing, China \\ henrryx@163.com \\ Linghui Wei \\ North China University of Technology \\ Beijing, China \\ weilh@ncut.edu.cn
}

\author{
$\mathrm{Xu}$ Kang \\ The Locomotive and Car Research Institute \\ China Academy of Railway Sciences \\ Beijing, China \\ kangxu@zemt.cn
}

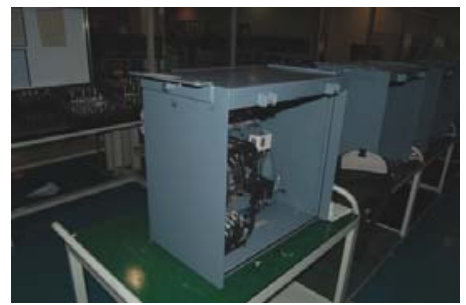

Figure 1. sheet metal class tank

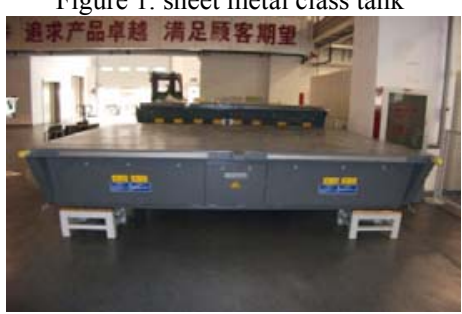

Figure 2. Framework classes tank

structure can be divided into two categories:

First class for sheet metal tank, that is the overall structure of the tank number for sheet metal parts, sheet metal parts connected by soldering, riveting, bonding or screw fastening process. Characteristics for this type of Cabinet is simple in structure, process less difficult and less structural strength, good used condition, loading small, the total weight is below $500 \mathrm{~kg}$, in product, and installation in the vehicle.As shown in Figure1.

Second case for frame classes, namely, the overall structure of the tank consists of a metal frame, metal frame sections, sheet metal bending, welding, carrying mainly consists of a metal frame inside and outside of the tank; Tank body outer steel plates welded, riveted, bonded or bolted connection processes connected with a metal frame, tank sealing and protective role. Such tankes are characterized by complex, difficult, the overall strength of high technology, more for the poor operating conditions, load, installed on the vehicle on the bottom or top of the product, product weight can even reach more than 3000kg.As shown in Figure2.[1].

\begin{abstract}
A lot of tank-type parts installed in the rail
vehicle, which as a function of the bearing parts and mechanical connections between vehicles of media, which is to ensure the functional parts and vehicles are properly corrosion and other factors outside interference. interface size, protection, strength of structure of demand is higher. Product focused way, you need to judge from the
\end{abstract}

Keywords- Rail,Brake,Metal tank,Parts, Welding,Process.

\section{INTRODUCTION TO METAL TANK-TYPE PARTS IN THE RAIL VEHICLE}


By Assembly relations, Cabinet by M8 stud welding and electro-mechanical through holes on the tank must correspond to each other. Mounting holes on the sheet metal laser cutting, and dimensional accuracy to within \pm $0.1 \mathrm{~mm}$.Fixing bolt for size M8, activities in the installation hole margin is less than $0.5 \mathrm{~mm}$. Due to the stainless steel welding deformation, to ensure that 16 weld studs can align mounting holes, it is very difficult to achieve.

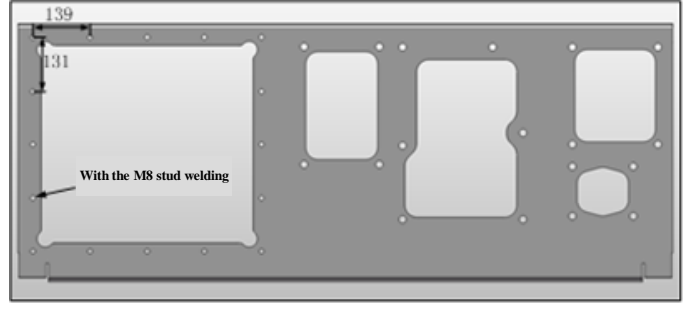

Figure 4. The rear panel

Early in the trial, usually only about 10 mounting holes to move smoothly into the bolt and staggered the remaining holes, some holes even deviate from the above $2 \mathrm{~mm}$, you cannot install the bolt. Deviations as shown in Figure5-8.

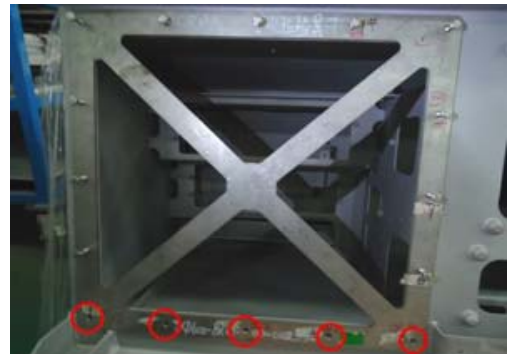

Figure5 1th Cabinet has 5 deviations

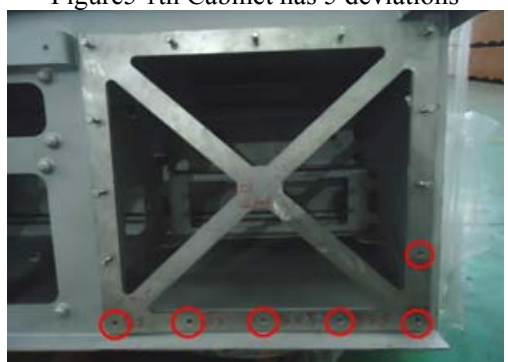

Figure 6. 2th Cabinet has 6 deviations

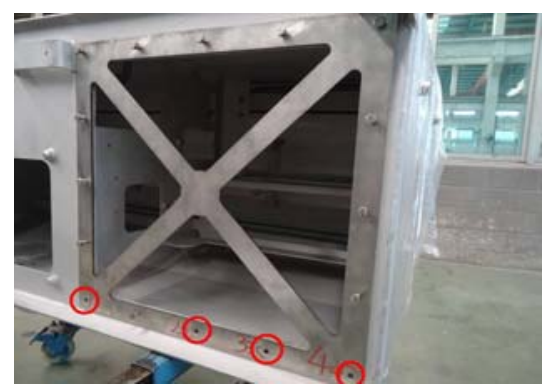

Figure 7. 3th Cabinet has 4 deviations

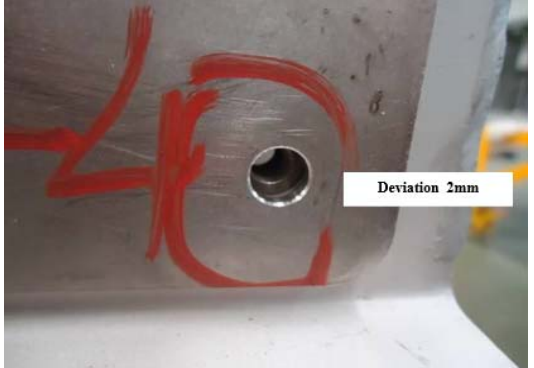

Figure 8.4th hole of 3rd Cabinet has $2 \mathrm{~mm}$ deviation

Through comparison of practice, decided to adopt alternative welding of stainless steel Cabinet of weathering steel. Weathering steels, namely atmospheric corrosion-resistant steel, is the range of normal steel and stainless steel, low-alloy series.09CuPCrNi-A the railway commonly used weathering steel material has been widely used for end of EMU traction chassis waiting for the manufacture of suspension parts[2].

\section{TEST OPTIONS}

In order to verify the corrosion resistant steel alternative to stainless steel in the aspect of technology advantages, designed the following test scenario:

1) Test programs:

Case1: Use 09CuPCrNi-A instead of stainless steel as the material of weld Cabinet, the remainder unchanged. Using special process equipment for welding, welding cooling after a period of time and then the equipment removed, measure 16 size relationship between the weld studs.

Case2: Use 09CuPCrNi-A instead of stainless steel as the material of weld Cabinet, and conversion of partially full weld to weld broken. Using special process equipment for welding, welding cooling after a period of time and then the equipment removed, measure 16 size relationship between the weld studs.

Due to the use of new materials, new technology, in order to fully demonstrate the feasibility process, after completion of the Cabinet the need for vibration testing, ensure the Cabinet structure to meet the requirements.

2) Test results:

Results of Case1:

Due to welding on the back panel of the Cabinet have more studs, prone to deformation, and therefore have to use technical equipment to be able to guarantee the dimension accuracy requirements.Among them, the Cabinet plate thickness $4 \mathrm{~mm}, 8 \mathrm{~mm}$ plain-carbon steel is chosen as base material of process equipment.Laser cutting, processing in the position corresponding to the stud of $\varphi 8$ vias.Electro-mechanical tank through hole for PHI 9, make some allowance for the post-weld deformation of the Cabinet.Process equipment as shown in Figure 9. 


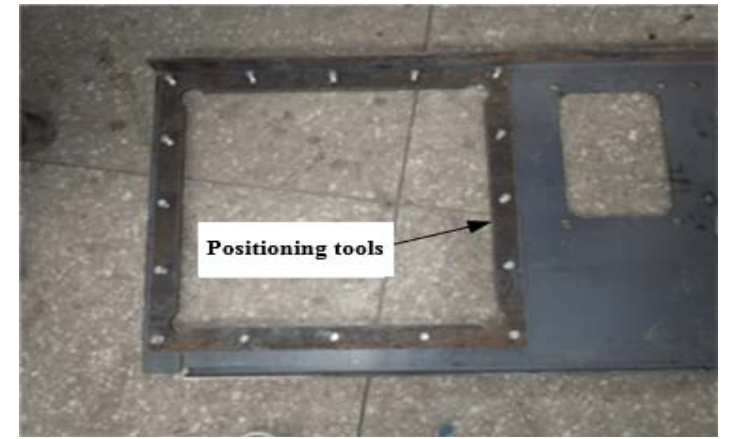

Figure 9. The process equipment photos

First position of technological equipment and the required welding studs are connected by bolts. Then 16 stud welding.Cannot be removed immediately after welding technique and equipment, back panel with the Cabinet Panel needs to be welded.Cabinet entirely after the welding is completed, age 1 day in a natural environment, and then remove the stud size measurement process equipment.Results as shown in Figure 10.

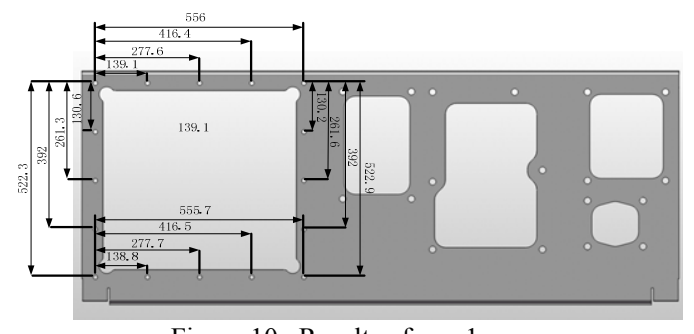

Figure 10. Results of case1

Results of case 2:

Second cabinet using the same welding sequence, using the same technique and equipment.Full weld around the Cabinet into intermittent welds. This change is based mainly on the basis of production technology of highspeed railway cars suspended below the tank.In order to verify the feasibility of this process change and vibration tests on the two cabinets. And the results of two processes to measure hole size, results are shown in Figure 11 and table 1.

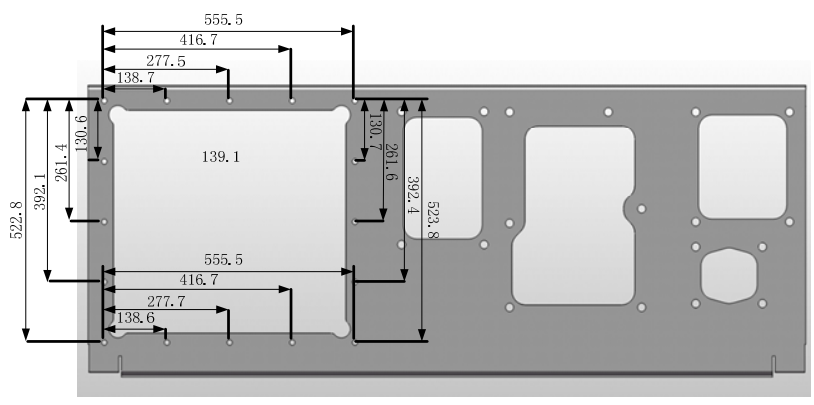

Figure 11. Results of case 1
Table 1 HOLE SIZE MEASUREMENTS AND DEVIATIONS RESULTS

\begin{tabular}{|l|l|l|l|l|l|l|l|l|}
\hline & \multicolumn{3}{|l}{ Full welded cabinets } & \multicolumn{3}{|l|}{ intermittent welded cabinets } \\
\hline $\begin{array}{l}\text { Th } \\
\text { eor } \\
\text { y }\end{array}$ & $\begin{array}{l}\text { masu } \\
\text { reme } \\
\text { nt }\end{array}$ & $\begin{array}{l}\text { Devi } \\
\text { ation } \\
\text { s }\end{array}$ & $\begin{array}{l}\text { masu } \\
\text { reme } \\
\text { nt }\end{array}$ & $\begin{array}{l}\text { Deviati } \\
\text { ons }\end{array}$ & $\begin{array}{l}\text { masure } \\
\text { ment }\end{array}$ & $\begin{array}{l}\text { Devi } \\
\text { ation } \\
\text { s }\end{array}$ & $\begin{array}{l}\text { ma } \\
\text { sur } \\
\text { em } \\
\text { ent }\end{array}$ & $\begin{array}{l}\text { Devi } \\
\text { ation } \\
\text { s }\end{array}$ \\
\hline 13 & 139. & 0.1 & 138. & -0.2 & 138.7 & -0.3 & 13 & -0.4 \\
\hline 27 & 277. & -0.4 & 277. & -0.3 & 277.5 & -0.5 & 27 & -0.3 \\
\hline 41 & 416. & -0.6 & 416. & -0.5 & 416.7 & -0.3 & 41 & -0.5 \\
\hline 55 & 556 & 0 & 555. & -0.3 & 555.5 & -0.5 & 55 & -0.5 \\
\hline 13 & 130. & -0.4 & 130. & -0.8 & 130.6 & -0.4 & 13 & -0.3 \\
\hline 26 & 261. & -0.7 & 261. & -0.4 & 261.4 & -0.6 & 26 & -0.4 \\
\hline 39 & 392 & -1 & 392 & -1 & 392.1 & -0.9 & 39 & -0.6 \\
\hline 52 & 522. & -1.7 & 522. & -1.1 & 522.8 & -1.2 & 52 & -0.2 \\
\hline
\end{tabular}

\section{GENETIC ALGORITHM}

Table 1 shows that, after using the new material as well as the use of special techniques and equipment, between studs is a high dimensional accuracy of, most of them in $1 \mathrm{~mm}$ to meet Assembly requirements.By analyzing the data can be found in welding, Panel shrinkage deformation. This is mainly due to sheet welding heat input resulting in a certain amount of shrinkage that occurs after cooling.Further improve welding deformation rule of use, prior to the weld studs of positioning hole processing certain shrinkage allowances.Welding dimension between studs is more close to the theoretical value.

Through these measurement results can be seen after using 09CuPCrNi-A instead of weathering steel stainless steel, reducing the deformation.And welding equipment, can effectively control production.Secondly, the cabinets intermittent welds, in most dimensions than welded Cabinet body closer to the theoretical value.Deviations up to $-1.7 \mathrm{~mm}$ the full weld Cabinet holes, broken weld Cabinet hole position deviation maximum position and welding machine Cabinet unanimously, but only $1.2 \mathrm{~mm}$.Full welded cabinet with an average deviation of $0.58 \mathrm{~mm}$, average deviation is a broken weld Cabinet $0.49 \mathrm{~mm}$. This description with intermittent weld can help reduce weld deformation. Therefore, in the case of certain complex structures, easy deformation, able to meet the requirements of the premise, intermittent welds can be used to improve dimensional accuracy[7].

\section{TEST RESULT ANALYSIS}

Table 1 shows that, after using the new material as well as the use of special techniques and equipment, between studs is a high dimensional accuracy of, most of them in $1 \mathrm{~mm}$ to meet Assembly requirements.By analyzing the data can be found in welding, Panel shrinkage deformation.This is mainly due to sheet welding heat input resulting in a certain amount of shrinkage that occurs after cooling.Further improve welding deformation rule of use, prior to the weld studs of positioning hole processing certain shrinkage 
allowances. Welding dimension between studs is more close to the theoretical value.

Through these measurement results can be seen after using 09CuPCrNi-A instead of weathering steel stainless steel, reducing the deformation.And welding equipment, can effectively control production.Secondly, the cabinets intermittent welds, in most dimensions than welded Cabinet body closer to the theoretical value.Deviations up to $-1.7 \mathrm{~mm}$ the full weld Cabinet holes, broken weld Cabinet hole position deviation maximum position and welding machine Cabinet unanimously, but only $1.2 \mathrm{~mm}$. Full welded cabinet with an average deviation of $0.58 \mathrm{~mm}$, average deviation is a broken weld Cabinet $0.49 \mathrm{~mm}$. This description with intermittent weld can help reduce weld deformation. Therefore, in the case of certain complex structures, easy deformation, able to meet the requirements of the premise, intermittent welds can be used to improve dimensional accuracy[4] [8].

\section{CONCLUSIONS}

Summary indicates that:1) Corrosion resistant steel 09CuPCrNi-A Cabinet and special process equipment to weld brake, brake Cabinet sizing is more accurate than the stainless can meet demanding Assembly requirements.2)Intermittent welds the Cabinet body smaller than a full welding deformation of the Cabinet, to meet under the premise, with intermittent weld Cabinet fitness to ensure accuracy.

\section{REFERENCES}

[1] Chinese Society of Mechanical Engineering Welding Branch.Welding Handbook. [M]BEIJING MACHINE PRESS.2003

[2] Xianqing Shu.Xingming Huang.Guowen Dai. The Control method of welding deformation in steel structure making. [J] Electric Welding Machine, 2007

[3] Ping Hang,Nengwen Liu. Welding deformation control of rail vehicle carrier bank.[J]. Welding\&Joining.2002（03）

[4] Ning Chen. The types and causes of welding deformation. [J] Railway Locomotive \& Rolling Stock Workers.2001 (01)

[5] Ning Chen. Prevention of welding deformation. [J] Railway Locomotive \& Rolling Stock Workers.2001 (02)

[6] Shuxiong Wu,Shike Yin,Chunfan Li. Welding of metallic materials Handbook. [M]Chemical Industry Press.2008

[7] Qianfang Li. Rail vehicle welding craft present situation and development trend.[J] Science and technology information of Heilongjiang.2014

[8] Bo Li. Rail vehicle stainless steel car body deformation analysis and solutions [J].Metal Working.2012 (12)

[9] Wenfeng Han. Rail vehicle welding technology and developing trend[J]. Science \& Technology Information.2014

[10] Chunmei Zhou,Lei Wang,DiWang. Discussion on welding deformation of low carbon steel sheets[J] Fortune World.2012(13) 